\title{
Alienation through Social Construction: A Call for the Re-humanization of Sexuality
}

\author{
Kathryn Coleman, MA \\ College of the Canyons \\ Los Angeles Valley College \\ Pasadena City College
}

\section{Social Construction of Sexuality}

Sexuality is a topic that comes with a great deal of controversy. The debate over whether sexuality is ascribed or achieved is an old and a loaded one. Often the same people (newscasters, elected officials, religious leaders, etc.) generating discussion on the topic misuse the proper terminology surrounding the subject, resulting in misleading and fallacious constructs being deployed and socially reinforced. While sexual orientation is ascribed (American Psychological Association, 2011), sexuality is a social representation of sexual orientation. So to argue whether one is born "gay" or "straight" is a loaded debate without the possibility of a solution because: People cannot be "gay" or "straight"; rather, only behaviors can be categorized in these binary constructs. However, sexual behaviors, social definitions, and interpretations of "gay" and "straight" as descriptors of human sexuality are constantly evolving. Thus, "gay" or "straight" can only be applied as descriptors to individual sexual actions rather than to people as a categorical approach to identity.

The American Sociological Association (ASA), American Medical Association (AMA), American Psychological Association, and American Pediatric Association all recognize sexuality as being experienced by the actor on a continuum and based on a personal sense of identity reflective of sexual attractions. The ASA, AMA, and American Psychological Association recognize that while there is no absolute consensus as to what determines one's sexual orientation, most people experience little or no sense of choice pertaining to their orientations, leading researchers to conclude, historically, that sexual orientation is biologically determined. "Although we can choose whether to act on our feelings, psychologists do not consider sexual orientation to be a conscious choice that can be voluntarily changed," (American Psychological Association, 2011). In addition, actors often portray sexual orientation through behaviors socially interpreted as indicative of that predetermined characteristic; however, sexual behavior may or may not reflect sexual orientation. In other words, the social actor has a choice whether to exercise behaviors indicative of current social definition of heterosexuality, homosexuality, bisexuality, or asexuality. The sexual behavior in which an individual engages does not necessarily reflect sexual orientation or desire; rather, sexual behavior is often indicative of the social construction of reality possessed by the social actor and of the motivations for specific sexual activity (Katz, 2007).

Despite behaviors exercised by the social actor, sexual orientation remains the same. So, while a social actor might have strong sexual urges for someone of the same sex category, they may never act on it. Conversely, someone having sexual attraction for others of the different sex may exercise behaviors indicative of current cultural definitions descriptive of homosexuality. Thus, behaviors often (mistakenly) become the catalyst for identifying others' sexual orientation. 
In addition, social actors' sexual behaviors are a product of socialization, not biology. For example, we learn (explicitly from parents, teachers, politicians, religious leaders, and other significant figures in our lives, or implicitly from images, themes, or messages in popular culture) how to have sex, with whom to have sex, with what motivations to have sex. We learn there are certain rules, social regulations, and even legislation controlling our interpretations of valuing our own and others' sexual behaviors. Sexual behaviors-focusing only on behaviors that are products of consensus from both (or all) parties - are behaviors (like all others) that are learned through socialization. They develop and progress as we develop and progress. Consequently, sexual behaviors are not always in response to sexual desire because of two central explanations: (1) Motivations for sexual behavior vary; and (2) The current social construction of normative sexual behavior is reflective of ultra-conservative (prudish) ideals and saturated with religious underpinnings - or at least the most current culturally valued behaviors are. Nevertheless sexual orientation remains inherent in individuals and, thus, unchanging.

Common terms pertaining to sexuality (sexual orientation, desire, and behavior) are constantly presented in the media as being interchangeable. However, they are not. Subsequently, much of the population is left uneducated (or inaccurately educated) due mainly to this misrepresentation in popular culture and media and to the lack of passable education in the public school system on this topic. Currently, there is no curriculum mandate for teaching human sexuality (vastly different from "sex ed"). This is in combination with the content of sex education most often resulting in the over-emphasis given to abstinence-only education (Landry, Darroch, Singh, Higgens, \& Donovan, 2003). Such restriction on students' access to fair and adequate education on human sexuality only adds to the distortion of sexuality commonly presented as "normative" in popular culture.

The inconsistency surrounding the use of the mentioned terminology (sexual orientation, sexual desire, and sexual behavior), the lack of education in our public schools, and limited interpretations of sexuality presented in the media have contributed to a poorly informed public. The incapacity to recognize the differences between these terms outside of the individual only enhances the risk of not being able to identify them correctly within the individual's experiences and the inability for one to fully understand their own complex sexuality. At risk is our ability to understand sexuality as one part of the human experience, instead of focusing on categories created in an attempt to indicate one's full social identity. The ability to separately define behaviors from orientation will allow actors to recognize sexuality as a continuum within the human experience with room for biological variation. After all, biology loves variation; it is we humans who tend to struggle with it.

\section{Capitalism, Inequality, and Sexuality}

Marx (1867/1965) predicted the expansion of "monopoly capitalism," wherein the ideas of capitalism would expand into a worldwide network of class conflict and exploitation (Marx, 1867/1965). Marx's view of society is, of course, valuable when exploring inequality, class, and social stratification within societies, yet also remains important when critically exploring the construction of sexuality in contemporary America, which will be addressed shortly. 
Marx argued that the exploitation of the proletariat was disguised by a facade of legitimacy. This facade is an explanation that members in the dominant groups give to justify their actions. These explanations are commonly based on "misleading arguments, incomplete analyses, unsupported assertions, and implausible premises" that ultimately support the dominant group (Carver, 1987, pp. 89-90). The most common facades of legitimacy include: (1) blaming victims by claiming character flaws that impede chances for success, and (2) claiming that the less successful benefit from the system established by the powerful. We should keep these facades in mind as we explore alienation and dehumanization within the current social construction of sexuality.

\section{Capitalist Alienation and Sexuality in Contemporary America}

Marx (1844/1978) was greatly concerned with the idea of people being alienated through capitalism. While Marx originally was writing to explain the effects on human potential in Western Europe's capitalist economies in the eighteenth and nineteenth centuries, his ideas of alienation are also applicable to the current construction of sexuality in modern society.

Marx (1844/1978) asserted that not only do workers (the proletariat) sell their labor power, but also their human capabilities. They have no power over the product that they are producing while their work is ultimately devoid of any redeeming human potentials (Marx, 1844/1978). Like the proletariat in Marx's writings, today's social actors no longer have control over the product of the social construction of sexuality. Social actors are producing the construction of sexuality without any real control over the product.

Current trends dictate specific sexual behaviors and social standards that individuals must obey in order to avoid social sanctions. There is a current social trend in which heterosexual behaviors (and identity) are culturally valued more than homosexual behaviors. This trend of devaluing homosexuality and behaviors often (mis)attributed with that category is observable in restrictive legislation (i.e., same-sex marriage rights; (Lewin, 2003), hate crimes perpetrated against the LGBTQ community (Bell \& Perry, 2015), the lack of representation of homosexuality in popular culture (Walters, 1998), the absence of education on homosexuality (and sexuality, in general) in public schools (Lindley \& Reininger, 2001), and high trends of occupational discrimination perpetrated against people identifying as, or believed to be, homosexual (Soucek, 2014). Here, we see examples of the first façade of legitimacy wherein those targeted are claimed to have character flaws that impede their chances of success while ultimately supporting the dominant group.

The loss of control over sexuality is blatantly apparent in the emphasis on the categorical constructs to which individuals must adequately ascribe. Further, these binary constructs are commonly presented as being finite and indissoluble. This leads to not only the doffing of human potential within the sexual sphere, but also provides a distraction from viewing sexuality as on a continuum. In addition, this trend reinforces the idea that people can be identified as an oversimplified social construction (gay or straight) rather than recognizing that sexual behavior is one aspect, though indeed complicated, of the human experience. 


\section{Dehumanization and Sexuality in Contemporary America}

Marx (1844/1978) also maintained that when human behaviors are repetitive and mimic those of a machine in a factory, the individual becomes dehumanized. The production process controls the worker because the wage earner has little or no control over the manufacturing of the goods. Further, the worker becomes alienated in the role of being a producer and from the product itself, because the owner of the factory determines the methods by which goods are produced. This also leads to the worker being alienated from herself since she is not exercising any real creativity or humanness; rather, she is mimicking the actions of a machine in a factory. She has become the machine.

According to Marx (1844/1978), capitalism provides profit for the owners of the means of production, but for those who have only their labor power to sell, they are subsequently restricted from seeing their human potential fulfilled. Within the domain of sexuality, there is also a ruling class benefitting from the current construction of sexuality. This ruling class is, of course, the people identified as being part of the heterosexual population through perception of behaviors. While not all people engaging in heterosexual behaviors belittle the idea that sexuality is not only a continuum and that the current sexuality hierarchy is not justifiable, this class is still the beneficiary of existing sexual inequalities because they are part of a class that is not regularly targeted for bigotry, prejudice, or discrimination based on sexual behaviors. Just as not all white people are bigoted in contemporary America, they are still the beneficiaries of white privilege that has been institutionalized within contemporary society.

Just as workers continued to work to make others more profit and were distracted from their need to engage in creative activities, most actors today are distracted from changing the current social construction of sexuality and continue to produce what has been constructed as a social ideal: Heterosexuality is more valuable within our current cultural narrative; thus the majority of social actors are more willing to publicly reproduce shared illustrations of the highly-valued heterosexuality. Due to the social reinforcement of heterosexual activity, many are afraid to either express behavior contradictory to current definitions of heterosexuality or to speak up and fight for social equality for those expressing behaviors indicative of homosexuality. This process reinforces the collective's dehumanized approach to sexuality.

The current trend of assigning people to sexual categories based on sexual behaviors and then dispensing values to those categories incites people to mimic actions in favor of the category that receives the most amount of social reinforcement. However, as noted earlier, people cannot be assigned as heterosexual or homosexual, rather only behaviors can be appropriately categorized as such. To reiterate, sexual orientation is ascribed, but cultural definitions of homosexual, heterosexual, and bisexual are continually changing. With the evolution of the definitions of each category, it is impossible to argue that anything more than behaviors can be placed into such categories. 


\section{Re-humanizing Ourselves: A Call for the Social De-construction and $R e$ - construction of Sexuality}

Marx (1844/1978) sought to create class consciousness - an awareness of the masses. He sought to facilitate class consciousness to begin the struggle for social change, ending the exploitation and alienation caused by the capitalist system and propagated by the ruling class. Somewhere along the way, including after the sexual revolution, the individual's control over the social construction of sexuality has been lost, while simultaneously producing sexuality as a binary social fact, perpetuating the falsity surrounding the topic and the dehumanization within it.

Much like the majority of socially normative behaviors, our sexual behaviors are constantly under scrutiny. As social actors, we are subject to a range of potential sanctions, both positive and negative, in response to our sexual behaviors. These sanctions, or the fear of such sanctions, are what stand in the way of real social change. Our social construction of sexuality and the inequalities bred from such construction, will not change without some serious social education and confrontation of current ignorant ideas surrounding sexual creed.

Therefore, in a spirit of positive sexuality this paper calls for a social de-construction and subsequent re-humanization of sexuality. This deconstruction should include: (1) a thorough understanding of the distinctions between the terms sexual orientation, sexual desires, and sexual behaviors; (2) a dismantling of the current agenda for sex education in our public schools that is fashioned through and confronted with political and religious opposition; and (3) social value being placed on diverse human experiences and potentials rather than the human ability to mimic constructed sexual ideals.

Perhaps the most effective approach to begin to reach these goals should target our educational institutions in an attempt to change sexually exclusive culture narratives. Allowing inclusive sex education in public schools (including curriculum focusing on the difference between sexual drive, desire, behaviors, and including positive role models for diversity in sexuality) will help "normalize" currently stigmatized sexual behaviors and people practicing those behaviors. Thorough sex education should thoroughly include physical, psychological, and social aspects of sexuality, not simply focusing on disease and pregnancy prevention.

While some people might argue that we may never be able to agree on values or morés pertaining to sexual behavior, we as a culture do share values and aspirations that are not difficult to uncover (Etzioni, quoted in Berreth \& Scherer, 1993). By implementing improved sex education in our schools, we will likely discover that the social and personal benefits of acceptable sex education outweigh the costs of lack of education. In American culture, we also generally agree that stigmatization and inflicting harm to others is unacceptable. A serious lack of formal sex education only allows these problems to flourish in our culture narrative.

Sex education does not necessarily require teaching certain values relating to particular sexual behaviors or current constructions of them. However, sex education should move beyond teaching anatomy, reproduction, and disease or pregnancy prevention (Haffner, 1992), and also include discussions pertaining to gender role socialization, interpersonal behavior, stigmatization, and acceptance. 
Such a positive shift in American culture would help socialize our youngest social actors toward a better understanding between sexual drive, desire, and behaviors, thus allowing for more thorough understanding and tolerance for their own sexual behaviors as well as sexual preferences of others. By not creating such a shift, we risk the permission to accept and value ourselves, as a collective people, for our diverse human experiences in contrast to an ability to mimic antiquated methods of discrimination through heteronormativity that are creating a dehumanization effect inherent to current sexual scripts. So, let's start the deconstruction process and begin reconstructing our sexual cultural narrative. Through education, acceptance, and an empathetic scope, we should see a re-humanization of ourselves.

\section{References}

American Psychological Association. (2011). Sexual orientation. Washington, DC: Author. Retrieved from: www.apa.org/topics/lgbt/orientation.aspx

Bell, J. G., \& Perry, B. (2015). Outside looking in: The community impacts of anti-lesbian, gay, and bisexual hate crime. Journal of Homosexuality, 62(1), 98-120.

Berreth, D., \& Scherer, M. (1993). On transmitting values: A conversation with Amitai Etzioni. Educational Leadership, 51, 12-15.

Carver, T. (1987). A Marx dictionary. New York: Barnes \& Noble.

Haffner, D.W. (1992). Foreword: Sexuality education in policy and practice. In J. T. Sears (Ed.), Sexuality and the curriculum: The politics and practices of sexuality education (pp. viviii). New York: Teachers College Press.

Katz, J. (2007). The invention of heterosexuality. Chicago, IL: University of Chicago Press.

Landry, D. J., Darroch, J., E., Singh, S., Higgins, J., \& Donovan, P. (2003). Factors associated with the content of sex education in U.S. public secondary schools. Perspectives on Sexual and Reproductive Health, 35, 261269.

Lewin, E. (2003). Same-sex marriage, legal mobilization, and the politics of rights. Journal of Marriage and Family, 65(4), 1085-1087.

Lindley, L. L., \& Reininger, B. M. (2001). Support for instruction about homosexuality in South Carolina public schools. The Journal of School Health, 71(1), 17-22.

Marx, K. (1867/1965). The class struggle. In T. Parsons, E. Shils, K. M. Naegele, \& J. Pitts (Eds.), Theories of society (pp. 529-535). New York: Free Press.

Marx, K. (1844/1978). Alienated labor: The economic and philosophic manuscripts of 1844. New York: W.W. Norton \& Company.
Soucek, B. (2014). Perceived homosexuals: Looking gay enough for Title VII. American University Law Review, 63(3), 715-788.

Walters, S. D. (1998). The gay next door (now in prime time). The Harvard Gay \& Lesbian Review, 5(2), 39. 